\title{
Acquired and Congenital Ocular Toxoplasmosis Experimentally Induced in Calomys callosus (Rodentia, Cricetidae)
}

\author{
Maria de Fátima Pereira, Deise Aparecida Oliveira Silva, \\ Eloisa Amália Vieira Ferro*, José Roberto Mineo/ ${ }^{+}$
}

\begin{abstract}
Laboratório de Imunologia, Departamento de Patologia *Laboratório de Histologia, Departamento de Morfologia, Universidade Federal de Uberlândia, Campus Umuarama, Av. Pará 1720, 38400-902 Uberlândia, MG, Brasil
\end{abstract}

An experimental model for acquired and congenital ocular toxoplasmosis as well as a model to induce experimental autoimmune uveitis (EAU) was investigated in Calomys callosus. Toxoplasma gondii, ME-49 strain, was used to infect males and pregnant-and not pregnant-females while S-antigen, a major glycoprotein of the retinal photoreceptor cell, was used to induce EAU. The ocular lesions elicited by T. gondii were characterized by the presence of cysts, free tachyzoites and inflammatory cells in the retina or related tissues. In the congenital form, $40 \%$ of the fetus presented ocular lesions, i.e., presence of cysts in the retina, vitreous, and extra-retinal tissues. In the acquired form, $75 \%$ of the females and 50\% of the males presented unilateral ocular cysts both at 21 and 47 days post-infection. It was also demonstrated that S-antigen was not uveitogenic in the C. callosus model. No lesion was observed in the animals exclusively immunized with this retinal component, even when jacalin was used as additional adjuvant for polyclonal response to the retinal antigen. It can be concluded that $\mathrm{C}$. callosus may constitute in a promising model for study both acquired and congenital ocular toxoplasmosis, particularly when it is important to make sure that a non autoimmune process is involved in the genesis of the ocular infection.

Key words: Calomys callosus - Toxoplasma gondii - acquired and congenital ocular toxoplasmosis - S-antigen

Toxoplasma gondii, an obligate intracellular parasite found in many animal species throughout the world, causes a variety of clinical syndromes in humans and animals. The infection is frequently assymptomatic and most cases of acquired Toxoplasma infection are subclinical. However, there are two groups of high-risk individuals: the human fetuses and the immunosuppressed patients (Favoreto-Jr et al. 1998). The prevalence of $T$. gondii-specific antibodies in adults increases with advancing age but differs widely with the geographic location (Lynfield \& Guerina 1997).

When congenital ocular toxoplasmosis is present in childhood, the infection may have interfered with the development of the eye (Dutton 1989). Uveitis is initiated in every instance by some form of tissue injury as, for example, the penetration of a single cell by an organism such as Toxoplasma (O'Connor 1983).

\footnotetext{
${ }^{+}$Corresponding author. Fax: +55-34-218.2333. E-mail: jrmineo@ufu.br Received 25 May 1998

Accepted 5 November 1998
}

Uveitis comprises a complex group of diseases and the mechanisms that lead to the initiation of this ocular inflammatory disease have been the subject of many investigations. An uveitogenic retinal agent (S-antigen) has been postulated to be involved in this disease. This soluble antigen presents a molecular weight of approximately $50 \mathrm{kDa}$ and has been purified from the photoreceptor region of bovine, human, rabbit, and guinea-pig retinas. An immunizing dose as low as $5 \mathrm{mg}$ of purified S-antigen injected at a distant site will induce a severe ocular inflammatory response in most laboratory animals tested (Nussenblatt et al. 1980).

Previous studies have shown that Calomys callosus (Rodentia, Cricetidae), a characteristic rodent in central Brazil, is an excellent experimental model for some parasitic infections (Mello 1981) and it was proposed as an alternative model to study acute phase of experimental toxoplasmosis (Favoreto-Jr et al. 1998).

The aim of this study was to assess the accomplishment of $C$. callosus as a new experimental model of acquired and congenital ocular toxoplasmosis. The maternal-fetal transmission of $T$. gondii was observed following experimental infection during the pregnancy and the transmission of the 
acquired disease was observed in males and pregnant and non-pregnant females. In addition, we evaluated if the uveitis could be induced either by antigenic similarity between $T$. gondii and S-antigen or by the exposition of the retinal antigen which occurred subsequently to the Toxoplasma infection.

\section{MATERIALS AND METHODS}

Animals - C. callosus (Canabrava strain) were obtained from a resident colony housed at the Laboratory of Histology from Universidade Federal de Uberlândia, MG, Brazil. The animals were approximately 2-3 months old males and females, and were kept on a $10 \mathrm{hr}$ light: $14 \mathrm{hr}$ dark cycle in a controlled room temperature $\left(25^{\circ} \mathrm{C}\right)$, with food and water ad libitum and supplemented with corn and sunflower seeds.

Parasites - T. gondii ME-49 strain parasites were obtained from brains of previously infected $\mathrm{BALB} / \mathrm{c}$ mice according to Brown et al. (1995). Brains were removed and washed with sterile saline, macerated and homogenized with needle and syringe, and submitted to the centrifugation at $1,000 \mathrm{~g}$ for $10 \mathrm{~min}$. A volume of $40 \mathrm{ml}$ of the suspension was placed on a glass microscope slide and the number of cysts was determined microscopically. In order to adapt the $T$. gondii ME-49 strain to C. callosus, animals were orally infected with 20 cysts obtained from brains of BALB/c mice inoculated at least 1 month earlier.

Mating - Three uninfected virgin females of $C$. callosus were housed in a cage with one male. The animals were inspected daily for the presence of vaginal plugs and the day of this evidence was designated as day 1 .

Pregnant female infection - In order to evaluate the development of acquired and congenital forms of toxoplasmosis in C. callosus, females from 5 to 7 days of pregnancy were orally infected with 20 cysts of $T$. gondii, ME-49 strain, obtained from brains of the animals used for strain adaptation. The females and their respective fetuses were killed at $15,16,17,18,19$ and 21 days of pregnancy. The mothers were anesthetized by ether inhalation and killed by cervical displacement after heart puncture. The fetuses were removed by laparatomy and decapitated. The maternal and fetal enucleated eyes were fixed in $0.01 \mathrm{M}$ phosphate buffered saline (PBS) pH 7.2 plus $10 \%$ formalin solution for $24 \mathrm{hr}$, and subsequently conditioned in $70 \%$ alcohol until the inclusion.

Infection of males and non pregnant females For evaluation of the evolution of acquired toxoplasmosis, 8 males and 4 virgin females were housed in separated cages and orally infected with 20 cysts of $T$. gondii, ME- 49 strain. The eyes of the animals were collected after 21 (4 males) or 47
(4 males and 4 females) days following infection as previously described.

Bovine S-antigen - S-antigen was obtained from bovine eyes, according to Wacker et al. (1977), with some modifications. These specimens were kindly provided by Frigorífico Triângulo, Uberlândia. The anterior portion of the ocular globe was removed by circumcorneal incision and the vitreous body and lens were dissected. A total of 100 retinas was separated from the choroid and epithelial pigment in a partially darkroom and conditioned in a beaker under ice-bath. A $20 \%$ suspension $(\mathrm{w} / \mathrm{v})$ of bovine retinas was prepared in extraction buffer $(0.1 \mathrm{M} \mathrm{NaCl}$ plus $0.05 \mathrm{M}$ potassium phosphate, $\mathrm{pH}$ 7.2), homogenized and centrifuged at 48,000 g for $3 \mathrm{hr} 30 \mathrm{~min}$. Proteins in the supernatant were precipitated by a half-saturated ammonium sulfate solution overnight at $4^{\circ} \mathrm{C}$. The precipitate was sedimented by centrifugation and dissolved in extraction buffer, dialyzed several times and submitted to gel filtration chromatography.

Gel filtration chromatography and SDS gel electrophoresis - A Sephadex G-100 column (2.5 $\mathrm{x} 100 \mathrm{~cm}$ ) was previously calibrated with extraction buffer and the retinal extract was applied, subsequently eluted with the same buffer and $3.5 \mathrm{ml}$ fractions were collected at a flow rate of $0.35 \mathrm{ml} /$ min. The protein content was measured spectrophotometrically at $280 \mathrm{~nm}$ and the protein fractions were pooled and concentrated to a volume of $5 \mathrm{ml}$. After being dialyzed, the samples of each fraction were diluted (v/v) at $10 \mathrm{mg} / \mathrm{ml}$ in sample buffer (0.1M TRIS pH 6.8, 4\% SDS - sodium dodecyl sulphate, $0.2 \%$ bromophenol blue and $20 \%$ glycerol), boiled for $3 \mathrm{~min}$ at $100^{\circ} \mathrm{C}$ and submitted to the SDS gel electrophoresis at $12 \%$ (Laemmli 1970 ) and further stained by silver (Zigler-Jr et al. 1984).

Experimental autoimmune uveitis (EAU) - In attempt to induce EAU, C. callosus specimens were divided in 10 groups and inoculated with S-antigen by intradermal or intramuscular routes and/or cysts of $T$. gondii ME-49 strain orally, with or without adjuvants, as follows: (1) 20 cysts of $T$. gondii ME-49 strain; (2) $50 \mathrm{mg}$ of S-antigen; (3) $50 \mathrm{mg}$ of S-antigen + CFA (Complete Freund's Adjuvant Difco Laboratories, Detroit, MI, USA); (4) $50 \mathrm{mg}$ of S-antigen $+100 \mathrm{mg}$ of jacalin (a soluble extract of Artocarpus integrifolia, as described by RoqueBarreira and Campos-Neto 1985); (5) $50 \mathrm{mg}$ of Santigen + CFA + $100 \mathrm{mg}$ of jacalin; (6) $50 \mathrm{mg}$ of Santigen +20 cysts of $T$. gondii ME-49 strain; (7) CFA; (8) $100 \mathrm{mg}$ of jacalin; (9) CFA + $100 \mathrm{mg}$ of jacalin; (10) PBS.

After 21 days of the immunization and/or infection, the animals were anesthetized by ether in- 
halation, bled by heart puncture and killed by cervical displacement and the eyes were enucleated and fixed as previously described.

Histopathological assays - The eyes were processed and included in historesin (glycol methacrylate, LKB 702218-500, Sweden), according to the manufacturer instructions. Sections of $2 \mathrm{~mm}$ thickness were made and collected at each $10 \mathrm{~mm}$. This procedure was adopted until approximately half of the ocular globe. The slides were stained with toluidin blue containing $1 \%$ borax and $1 \%$ toluidin for $30 \mathrm{sec}$ and preserved in entellan (Merck, Darmstadt, Germany) covered by cover-slips. Finally, the material was analyzed for the presence of cysts or free tachyzoites or inflammatory cells by three independent observers who did not know in advance the identification of the groups from this study.

Serological assays - Enzyme-linked immunosorbent assay (ELISA) was carried out for detection of antibodies to S-antigen and $T$. gondii, as described (Mineo et al. 1980), with some modifications. Microtiter plates (Interlab Diagnóstica SA) were coated either with a soluble extract of $T$. gondii RH strain tachyzoites $(2.5 \mathrm{mg} / \mathrm{ml})$ or S-antigen $(10$ $\mathrm{mg} / \mathrm{ml}$ ) in $0.06 \mathrm{M}$ sodium carbonate buffer $\mathrm{pH} 9.6$ overnight at $4^{\circ} \mathrm{C}$. The plates were washed three times with PBS containing $0.1 \%$ Tween-20 (PBST) and incubated with the $C$. callosus serum samples at dilution of 1:32 in PBST for $45 \mathrm{~min}$ at $37^{\circ} \mathrm{C}$. Positive and negative serum controls were included on each plate. After repeated washing, it was added peroxidase-labeled rabbit IgG anti-C. callosus gama-globulin conjugate which was prepared as described by Wilson and Nakane (1978). This reagent was used at 1:1000 dilution in PBST and incubated for $45 \mathrm{~min}$ at $37^{\circ} \mathrm{C}$. After final wash, it was added the substrate, consisting of hydrogen peroxide and o-phenylenediamine (Merck, Germany) in $0.1 \mathrm{M}$ citrate- $\mathrm{Na}_{2} \mathrm{HPO}_{4}$ buffer (pH 5.5) for $15 \mathrm{~min}$ at room temperature. The enzymatic reaction was stopped with $2 \mathrm{~N} \mathrm{H}_{2} \mathrm{SO}_{4}$ and the absorbance was determined at $492 \mathrm{~nm}$ using a microplate reader (Titertek Multiskan Plus, Flow, USA). The cut-off values were arbitrarily determined as those exceeding the mean absorbance plus three standard deviations obtained for the negative controls.

Western-blotting (WB) - In order to detect antigenic bands from $T$. gondii and S-antigen recognized by the $C$. callosus serum samples, the WB technique was carried out according to Towbin et al. (1979). The respective soluble antigenic extracts and molecular weight standards (Sigma Chem. Co., St. Louis, MO, USA) were submitted to electrophoresis in SDS-PAGE at $12 \%$ (Laemmli 1970). After SDS-PAGE, gels were transferred to a nitro- cellulose membrane (Sigma Chem. Co.) and the protein-binding sites were blocked with $5 \%$ nonfat milk in $0.05 \%$ Tween 20-PBS for $2 \mathrm{hr}$ at room temperature. Strips were incubated with $C$. callosus serum samples diluted at 1:50 in 1\% nonfat milk$0.05 \%$ Tween 20-PBS (dilution buffer) overnight at $4^{\circ} \mathrm{C}$. After several washings with dilution buffer, the strips were incubated for $2 \mathrm{hr}$ with peroxidaserabbit IgG anti-C. callosus gama-globulin conjugate diluted at 1:500 in dilution buffer. The strips were washed and revealed by hydrogen peroxide plus 3'3' tetra-diamino-benzidine tetrahydrochloride (DAB) in PBS. The reaction was stopped by washing with $\mathrm{H}_{2} \mathrm{O}$.

\section{RESULTS}

Bovine S-antigen purification - Samples from each step of the retinal extract purification process by gel filtration were applied in SDS-PAGE and stained by silver. The fraction containing S-antigen was shown as a single band of $50 \mathrm{kDa}$, approximately (lane 9, Fig. 1).

Induction of experimental uveitis - After S-antigen purification, $50 \mathrm{mg}$ doses were inoculated with or without various adjuvants by intradermal or intramuscular routes in attempt to induce ocular lesion in different groups of animals. As shown in Figs 2 and 3, no histopathologic features that could indicate the presence of EAU were seen in these respective groups. In contrast, the animals orally infected with $T$. gondii ME-49 strain cysts presented retinal cyst and cones- and rods-layer alterations which are attributes of toxoplasmic uveitis (Figs 4, 5).

Acquired and congenital ocular toxoplasmosis in pregnant females - The ocular lesion caused by T. gondii was characterized by the presence of parasitic cysts, free tachyzoites and/or inflammatory cells in the retina or sustentation layer (Table I). The presence of inflammatory cells was a rare event in most of the animals (fetuses and adults) with ocular cysts, or even in those with free tachyzoites in the retina. From a total of 25 fetuses that had been studied, 10 (40\%) presented ocular lesion characterized by presence of cysts in: retina (16\%), vitreous $(8 \%)$, retina external tissues (8\%), optic nerve (4\%) and lens (4\%) (Figs 6-11). The 15 remaining fetuses (60\%) did not present ocular lesion. Samples from six pregnant females that have been examined, $3(50 \%)$ presented ocular lesion and among these, $1(33 \%)$ presented retinitis with destruction of the cones- and rods-layer (Figs 12, 13).

Acquired ocular toxoplasmosis in males and non pregnant females - Males and non pregnant females after 21 or 47 days of infection were examined for the presence of the acquired form of the disease, without influence of pregnancy fac- 


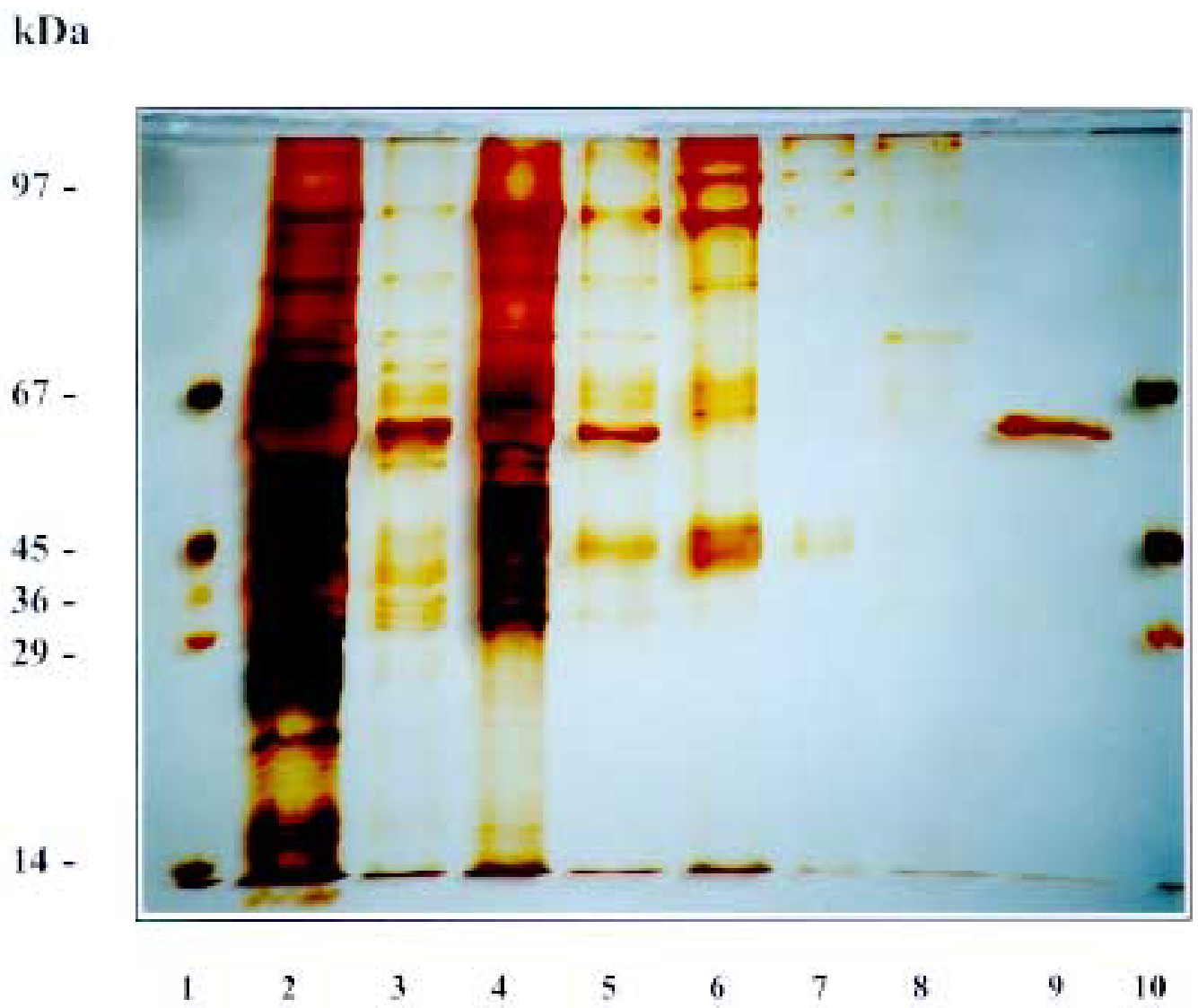

Fig. 1: silver-stained SDS gel electrophoresis (12\%) of retinal extracts before and after purification in Sephadex G-100. Lane 1, low molecular weight standards; lane 2 , crude retinal extract $(50 \mathrm{mg})$; lane 3 , crude retinal extract (10 mg); lane 4, half-saturated ammonium sulfate precipitated extract $(20 \mathrm{mg})$; lane 5, half-saturated ammonium sulfate precipitated extract (5 mg); lane 6 fraction $1(25 \mathrm{mg})$; lane 7 , fraction $1(5 \mathrm{mg})$; lane 8 , fraction $2(5 \mathrm{mg})$; lane 9 , fraction $3(5 \mathrm{mg})$; lane 10, high molecular weight standards.

tors (Table II). Among the males with 21 days postinfection, $50 \%$ presented retinal cysts in the absence of inflammatory cells (Figs 14, 15). Animals with 47 days post-infection presented cysts and/or inflammatory cells in the retina, vessels and sustentation layer. It was estimated that $75 \%$ of the females presented unilateral lesion (cysts) and 25\% of the males presented unilateral lesion (cysts), while $25 \%$ of them presented bilateral lesion (cysts in an eye and inflammatory process in contralateral eye) (Figs 16-19).

Serological evaluation and WB - Antibodies against $T$. gondii and $\mathrm{S}$-antigen were examined in serum samples at dilution of 1:32. Table III shows the reactivity of various groups of animals orally infected with cysts of $T$. gondii ME-49 strain or immunized with S-antigen, associated or not with

\section{TABLE I}

Acquired and congenital ocular toxoplasmosis in Calomys callosus infected orally with 20 cysts of the Toxoplasma gondii ME-49 strain at 5 or 7 days of pregnancy

\begin{tabular}{ccccc}
\hline $\begin{array}{c}\text { Pregnancy time } \\
\text { (days) }\end{array}$ & & & \multicolumn{2}{c}{$\begin{array}{c}\text { Presence of } \\
\text { ocular lesion }\end{array}$} \\
\cline { 1 - 2 } \cline { 5 - 6 } At infection & At analysis & & Pregnant females & Fetus \\
\hline 5 & 15 & & - & $1 / 4$ \\
7 & 16 & & - & $3 / 5$ \\
5 & 17 & & + & $0 / 3$ \\
5 & 18 & & + & $2 / 6$ \\
7 & 19 & & - & $2 / 3$ \\
7 & 21 & & + & $2 / 4$ \\
\hline
\end{tabular}



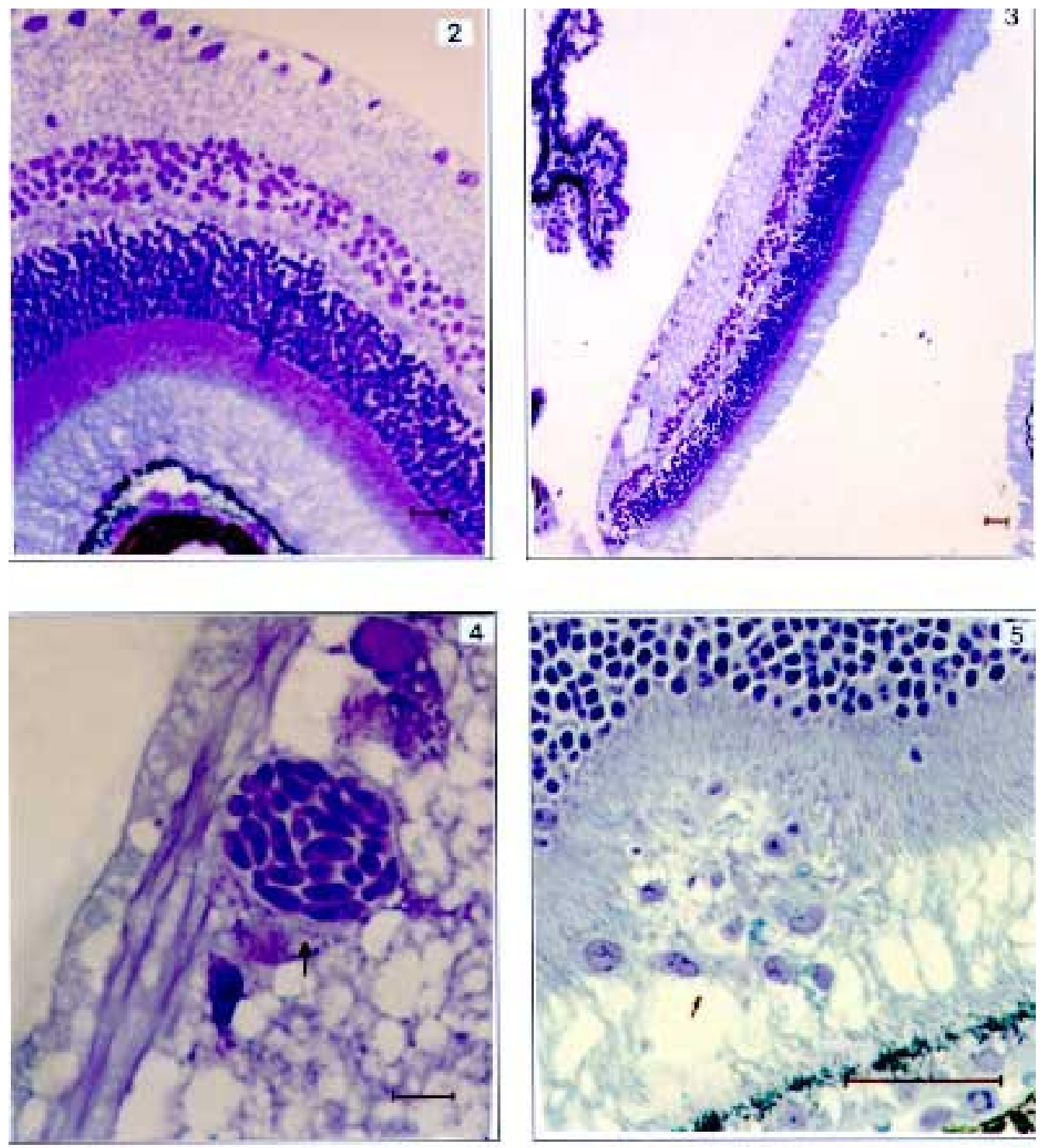

Micrographs of eye section, stained by toluidin blue, from Calomys callosus, adult male, after 21 days of being treated with one of the following conditions. Fig. 2: immunization with S-antigen. Fig. 3: immunization with S-antigen plus jacalin. Figs 4, 5: immunization with S-antigen plus infection with 20 cysts of Toxoplasma gondii. Bar $=10 \mathrm{~mm}$.

different adjuvants. It was observed a great dispersion of the values from different groups. However, in general the antibodies were detected in all homologue groups. It was observed that the presence of antibodies directed to the retinal antigen was not related with the presence of the ocular lesion. To assess the specificity of the antibody detection by ELISA, it was carried out the western blot reaction with those samples that presented unclear results.

The WB results obtained from serum samples of C. callosus of the different groups when S-anti-
TABLE II

Acquired ocular toxoplasmosis in Calomys callosus infected orally with 20 cysts of the Toxoplasma gondii ME-49 strain

\begin{tabular}{lccc}
\hline Sex & $\begin{array}{c}\text { Time } \\
\text { Post-infection } \\
\text { (days) }\end{array}$ & $\begin{array}{c}\text { Presence of ocular } \\
\text { lesion among the } \\
\text { infected animals }\end{array}$ & $\begin{array}{c}\text { Type of } \\
\text { ocular } \\
\text { lesion }\end{array}$ \\
\hline Male & 21 & $2 / 4$ & Unilateral \\
Male & 47 & $2 / 4^{a}$ & Unilateral \\
Female & 47 & $3 / 4$ & Unilateral \\
\hline
\end{tabular}

$a$ : an animal presented bilateral ocular lesion. 

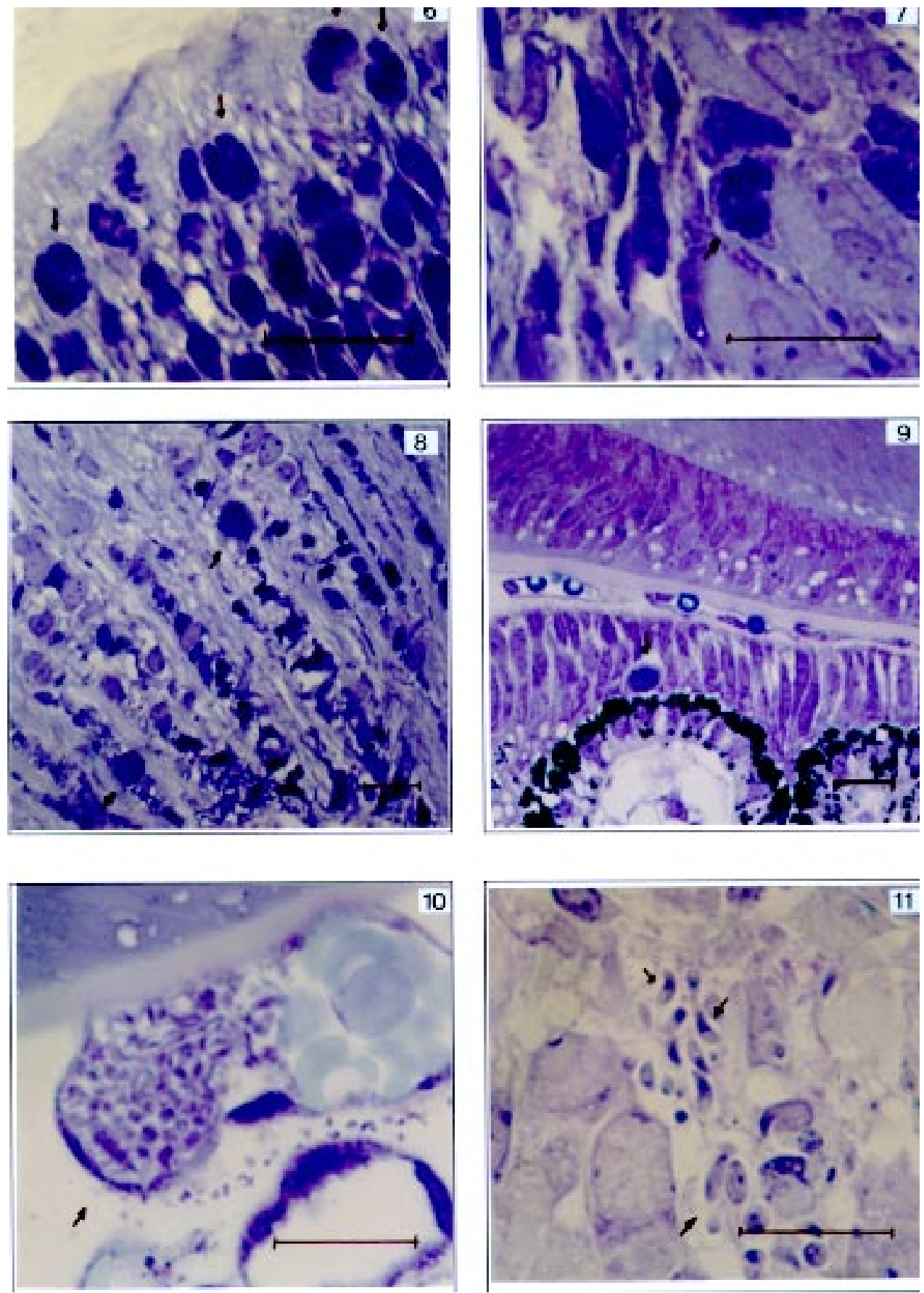

Micrographs of eye section, stained by toluidin blue, from fetuses of Calomys callosus which mothers had been infected perorally with 20 cysts of Toxoplasma gondii. Fig. 6: lens from fetus presenting 16 days of development and 9 days of infection; arrow indicates cysts. Fig. 7: retina adjacent tissues from fetus presenting 16 days of development and 9 days of infection; arrow indicates cyst. Fig. 8: optic nerve from fetus presenting 18 days of development and 13 days of infection; arrows indicate cysts. Fig. 9: retina from fetus presenting 21 days of development and 14 days of infection; arrow indicates cyst. Fig. 10: vitreous of fetus presenting 19 days of development and 12 days of infection, without inflammatory reaction; arrow indicates cysts nearby a blood vessel. Fig. 11: retina from fetus presenting 21 days of development and 14 days of infection; arrows indicate free tachyzoites, without inflammatory reaction. Bar $=10 \mathrm{~mm}$. 

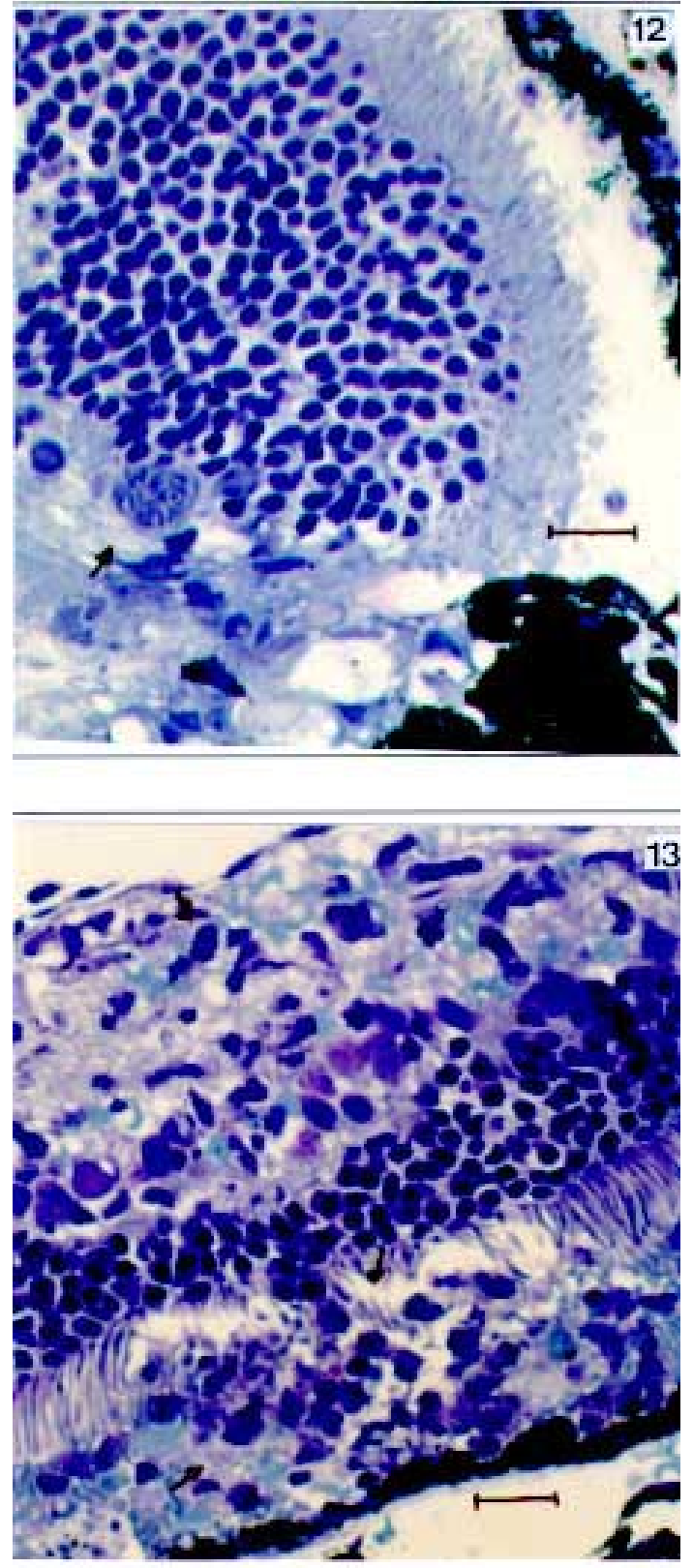

Micrographs of eye section, stained by toluidin blue, from Calomys callosus, pregnant females, infected orally with 20 cysts of Toxoplasma gondii. Fig. 12: retina of animal with 21 days of pregnancy and 12 days post-infection; arrow indicates cyst. Fig. 13: retina of animal with 17 days of pregnancy and 12 days post-infection; arrows indicate presence of inflammatory cells (neuthrophils). Bar $=10 \mathrm{~mm}$.

gen was immobilized in the nitrocellulose membrane are showed in Fig. 20. The animals immunized with S-antigen only showed a weak intensity of antibody response to this antigen (lane 1), while those immunized with S-antigen + CFA associated or not with jacalin revealed a strong reac-
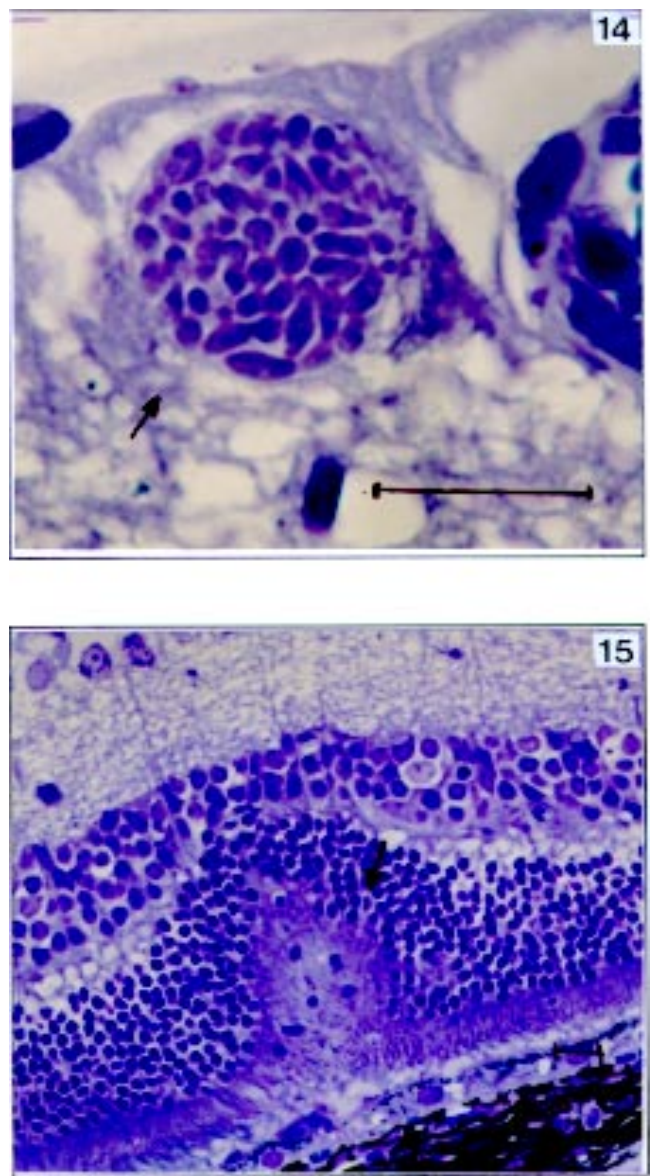

Micrographs of eye section, stained by toluidin blue, from Calomys callosus, adult male, infected orally 21 days before with 20 cysts of Toxoplasma gondii. Fig. 14: retina without inflammatory reaction; arrow indicates cyst of $T$. gondii. Fig. 15: retina presenting morphological changes; arrow indicates alterations in the retinal layers. Bar $=10 \mathrm{~mm}$.

tivity to S-antigen (lanes 2 and 4, respectively). It was also observed reactivity for other two bands $>$ $67 \mathrm{kDa}$ (lanes 2 and 4). There was no detection of antibody synthesis to $\mathrm{S}$-antigen in the animals immunized with either S-antigen + jacalin, or jacalin or CFA only or jacalin + CFA (lanes 3, 5, 6 and 7, respectively). In contrast, it was observed a weak antibody response to $S$-antigen when the animals had been infected with $T$. gondii ME-49 strain, even following 47 days of infection (lane 8) while a strong reactivity was observed in the animals that had been immunized with ME-49 strain + jacalin at 21 days post-infection (lane 9). Serum samples of $C$. callosus inoculated with the $T$. gondii $\mathrm{RH}$ strain as well as sera of uninfected animals showed no reactivity to S-antigen (lanes 10 and 11). 

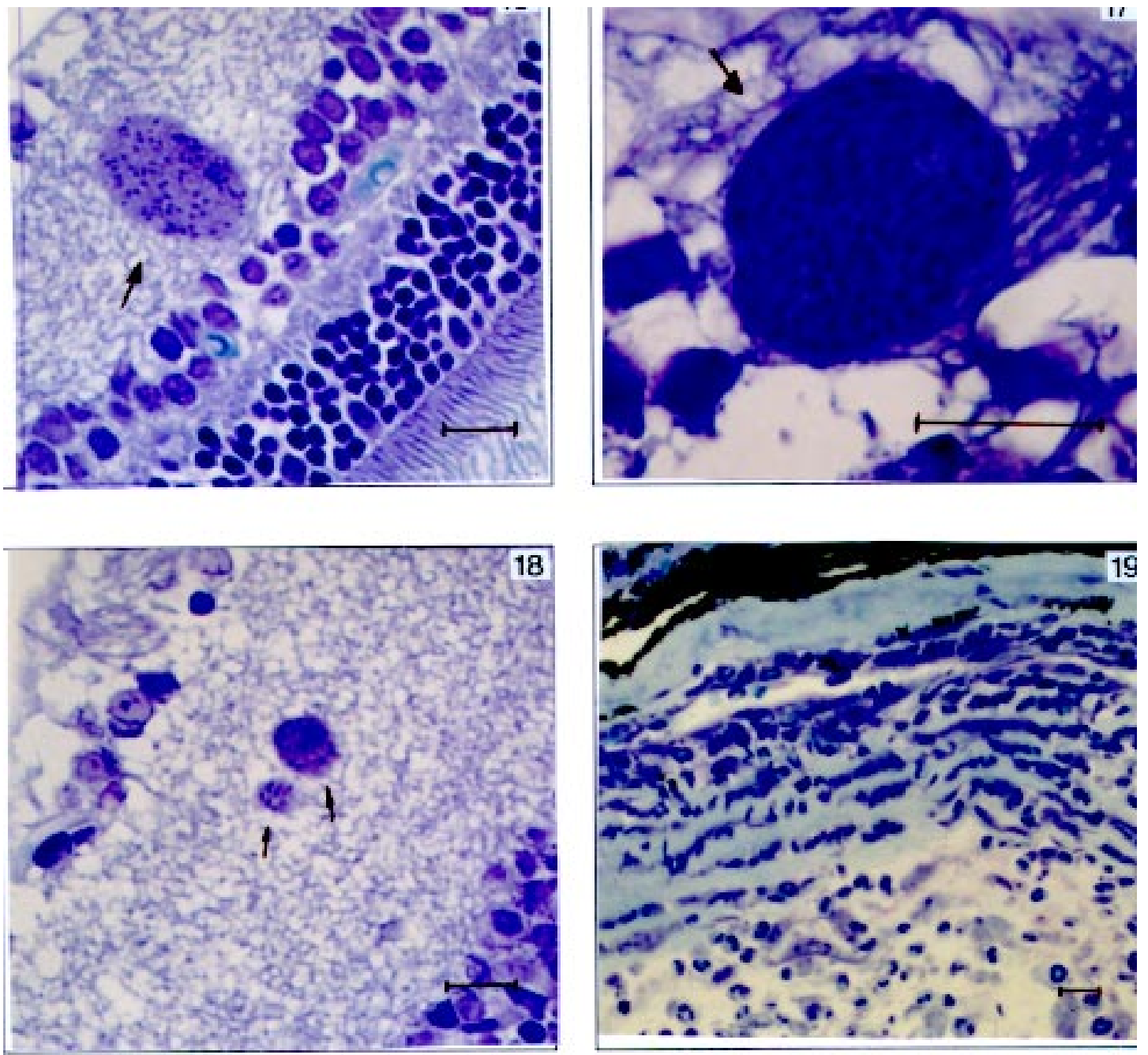

Micrographs of eye section, stained by toluidin blue, from Calomys callosus, at 47 days post-infection with 20 cysts of Toxoplasma gondii, perorally. Figs 16, 17: retina from non-pregnant female; arrows indicate presence of retinal cysts without inflammatory reaction. Fig. 18: retina from adult male; arrows indicate presence of retinal cysts without inflammatory reaction. Fig. 19: retinal adjacent tissues from adult male; presence of intense inflammatory process. Bar $=10 \mathrm{~mm}$.

\section{TABLE III}

Reactivity for Toxoplasma gondii and S-antigen determined by ELISA in serum samples from groups of Calomys callosus infected or immunized with various immunogens

Groups of animals infected or inoculated with various immunogens
Detection of antibodies in serum samples at dilution of $1 / 32$ (mean absorbance \pm standard deviations)

\begin{tabular}{lcc}
\cline { 2 - 3 } & Anti-T. gondii & Anti-S-antigen \\
\hline T. gondii ME-49 & $.447( \pm .078)$ & $.310( \pm .145)$ \\
S-antigen & $.313( \pm .249)$ & $.382( \pm .125)$ \\
S-antigen + CFA & $.279( \pm .151)$ & $.638( \pm .209)$ \\
S-antigen + jacalin & $.264( \pm .125)$ & $.395( \pm .246)$ \\
S-antigen + CFA + jacalin & $.190( \pm .136)$ & $.515( \pm .220)$ \\
S-antigen + ME-49 + CFA & $.385( \pm .032)$ & $.312( \pm .112)$ \\
CFA & $.242( \pm .081)$ & $.255( \pm .052)$ \\
Jacalin & $.225( \pm .164)$ & $.245( \pm .096)$ \\
CFA + jacalin & $.489( \pm .210)$ & $.439( \pm .176)$ \\
PBS (Control) & $.116( \pm .089)$ & $.288( \pm .137)$ \\
\hline
\end{tabular}




\section{kDa}

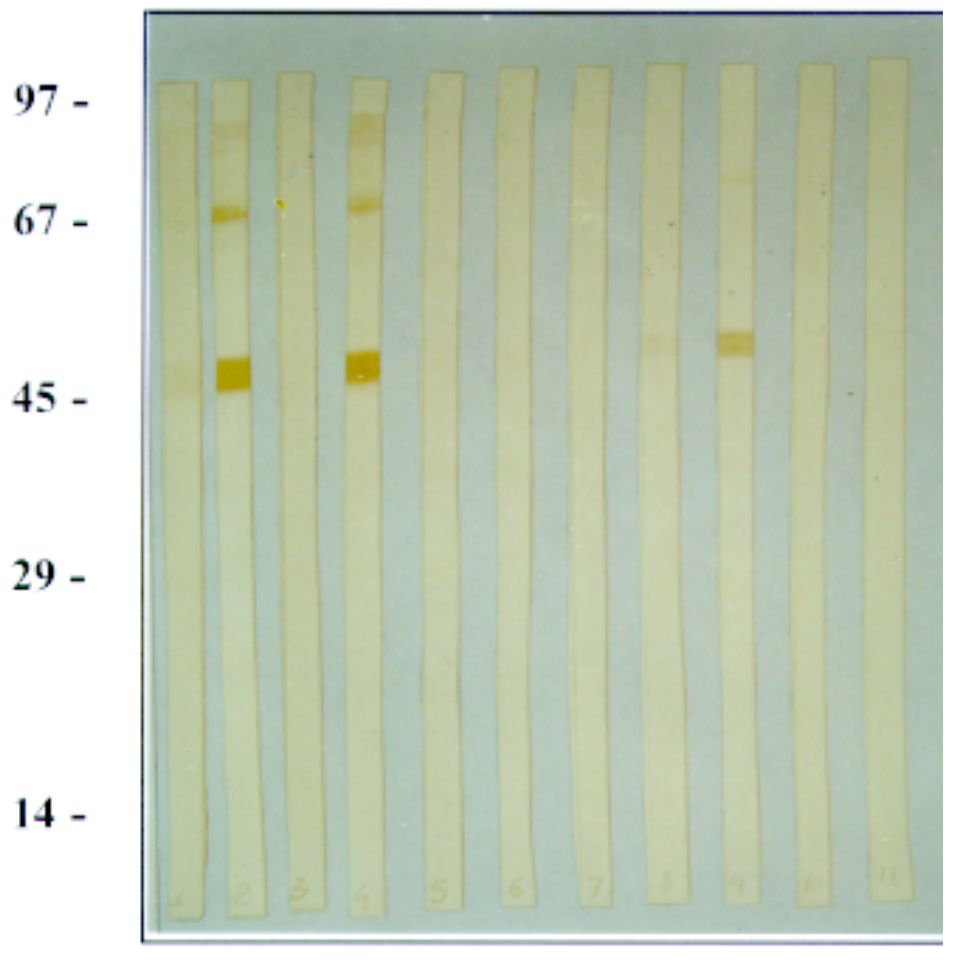

$\begin{array}{lllllllllll}1 & 2 & 3 & 4 & 5 & 6 & 7 & 8 & 9 & 10 & 11\end{array}$

Fig. 20: Western-blot of S-antigen, purified from bovine retina, recognized by serum samples of Calomys callosus, immunized with: lane 1, S-Antigen (50 mg); lane 2, S-Antigen (50 mg) and CFA (1 mg/ml); lane 3, S-Antigen (50 mg) and jacalin (100 mg); lane 4, S-Antigen $(50 \mathrm{mg})$, jacalin $(100 \mathrm{mg})$ and CFA $(1 \mathrm{mg} / \mathrm{ml})$; lane 5, jacalin $(100 \mathrm{mg}) ;$ lane 6 , CFA $(1 \mathrm{mg} / \mathrm{ml}) ;$ lane $7, \mathrm{CFA}(1 \mathrm{mg} / \mathrm{ml})$ and jacalin (100 mg); lane 8, 20 cysts of Toxoplasma gondii, strain ME-49, by oral route, after 47 days of infection; lane 9, 20 cysts of $T$. gondii, strain ME-49, by oral route, after 21 days of infection and jacalin (100 mg); lane 10, positive serum sample control; lane 11 , negative serum sample control.

Fig. 21 shows the WB results when $T$. gondii antigen was immobilized in the nitrocellulose membrane. In all studied groups, that is, animals immunized with only S-antigen and/or S-antigen associated to CFA or jacalin as adjuvants, it was not possible to detect antibodies anti-T. gondii (lanes 1 to 7). On the other hand, the animals infected with $T$. gondii ME-49 strain showed a characteristic profile of antibodies to the major antigens of this parasite (lanes 8 and 9), in consonance to the profile obtained with sera of animals inoculated with $T$. gondii RH strain (lane 10) and absence of antibodies in non-inoculated animals (lane 11).

\section{DISCUSSION}

The utilization of experimental models to study congenital and acquired ocular toxoplasmosis ap- pears to be mandatory to understand the different factors influencing ocular lesion induced by $T$. gondii. C57BL/6 mice infected with the ME-49 strain of this parasite develop a progressive meningoencephalitis, which is initially characterized by the presence of occasional cysts and scattered neuronal necrotic foci with microglial and lymphocytic infiltrates (Gazzinelli et al. 1994).

C. callosus has demonstrated to be an animal of easy handle in laboratory allowing a gestational phase following-up for the fetal study. It survives to infection with the $T$. gondii ME-49 strain for several months without treatment and demonstrating no clinical signs of the disease.

In human and murine models, vertical transmission of $T$. gondii occurs from acutely infected 


\section{kDa}

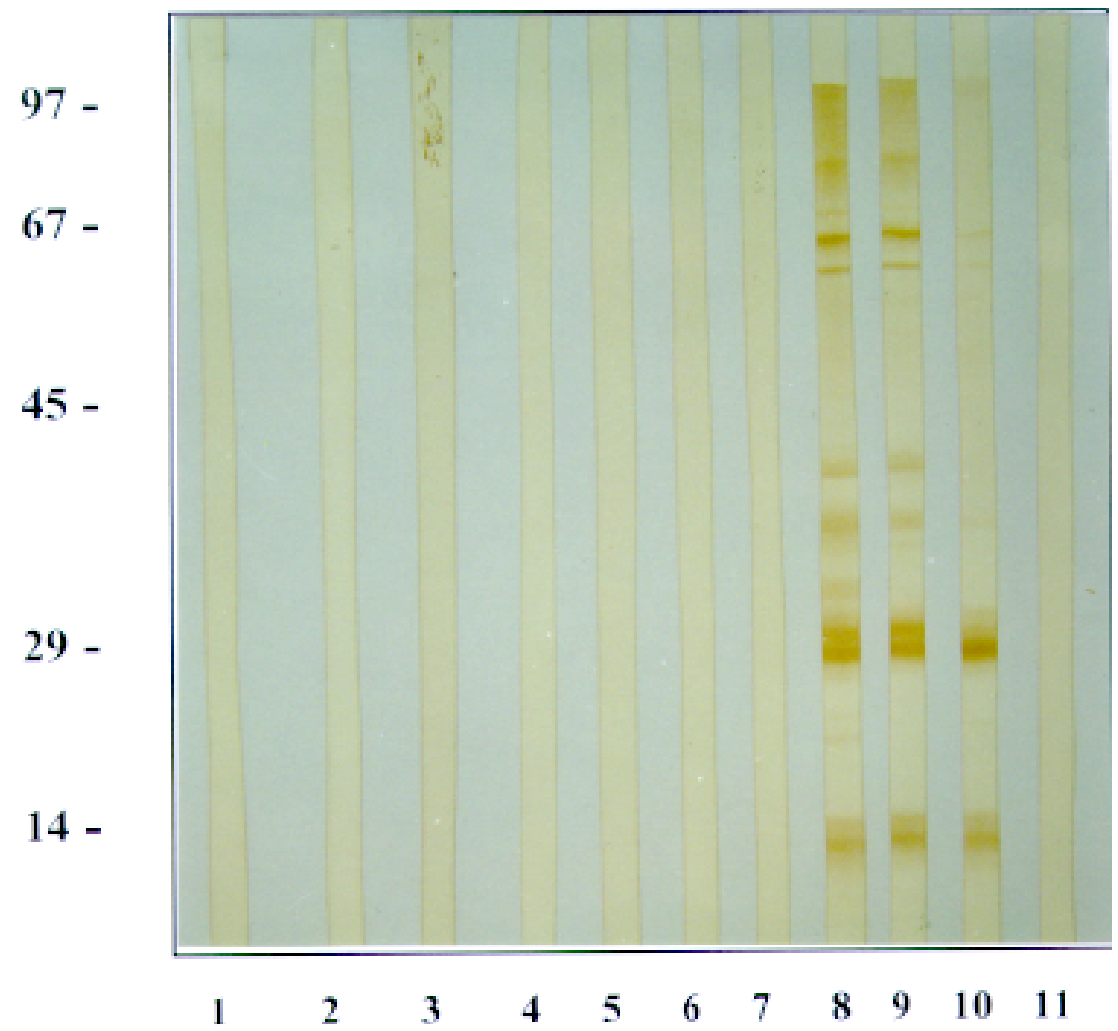

Fig. 21: Western-blot of Toxoplasma gondii antigen-specific markers recognized by serum samples of Calomys callosus, immunized with: lane 1 , S-Antigen $(50 \mathrm{mg})$; lane 2, S-Antigen $(50 \mathrm{mg})$ and CFA (1 mg/ml); lane 3, S-Antigen $(50 \mathrm{mg})$ and jacalin (100 $\mathrm{mg})$; lane 4, S-Antigen (50 mg), jacalin (100 mg) and CFA (1 mg/ml); lane 5, Jacalin (100 mg); lane 6, CFA (1 mg/ml); lane 7, CFA $(1 \mathrm{mg} / \mathrm{ml})$ and jacalin $(100 \mathrm{mg})$; lane 8, 20 cysts of $T$. gondii, strain ME-49,by oral route, after 47 days of infection; lane 9, 20 cysts of $T$. gondii, strain ME-49,by oral route, after 21 days of infection and jacalin $(100 \mathrm{mg})$; lane 10, positive serum sample control: lane 11, negative serum sample control.

mothers to her fetus (Lynfield et al. 1997). Transmission rates appear to correlate well with placental blood flow: the risk of fetal infection may be as low as $1 \%$ or less when maternal infection occurs in the periconception period and as high as $90 \%$ or greater when maternal infection occurs near term. The average transmission rate is approximately $15 \%$ for the first trimester, $30 \%$ for the second trimester, and 60\% for the third trimester (Lynfield et al. 1997). Since the reproductive cycle of $C$. callosus is approximately three weeks, it might be considered the first pregnancy week as corresponding to first gestational trimester in humans. In the present study the occurrence of ocular toxoplasmosis was of $40 \%$ in the fetuses from mothers infected at 5 or 7 days of pregnancy. Probably, the remaining fetuses could contain the parasite in other organs but the eye. It was possible to verify the presence of parasites in the fetal placentas of this study (data not showed). Thus, it seems that ocular toxoplasmosis in those fetuses could occur in a later period.

According to Gonçalves and Yamamoto (1997), the retina is the primary site of Toxoplasma infection. Toxoplasma antigens probably reach the eye by bloodstream as would occur during the congenital or acquired infection (Newman et al. 1982). Thus, the majority of intra-retinal cases of cyst formation probably occurs as a result of pre-or postnatal parasitaemia. These cysts may remain dormant within the retina and other tissues. It has also proposed that the parasites might gain access to the eye by passage along the optic nerve (Dutton 1989).

It was observed in the present study that the most of the animals presented unilateral cysts in 
the retina. In the congenital form, $16 \%$ of the fetuses presented cysts in the retina and the remaining in another areas such as lens, vitreous, optic nerve and tissues from sustentation layers. In some fetuses, the presence of cyst was verified adjacent to a vessel in the vitreous. Perhaps, these cysts have developed in the parenquimal cells during the embryonic development, but further studies are necessary to clarify this subject.

In C. callosus, the fetal retina showed little differentiation in the layers, with significant vascularization as it occurs with the embryonic retina from humans which does not present individualization of the layers, becoming avascular during the fetal period (Moore 1990).

Rothova et al. (1986) suggest that ocular involvement has rarely occurred in cases of acquired toxoplasmosis in humans. Nogueira et al. (1996) reported that during the acquired toxoplasmosis, generally unilateral retinochoroiditis could occur in $1-2 \%$ of the human cases. However, it has been observed that the incidence of acquired ocular toxoplasmosis may be high in some geographical areas. The Erechim, RS, Brasil is a region with the highest incidence of this form of ocular toxoplasmosis in the world and it has been suggested that this might be related to the popular habit of ingesting raw meat (Silveira et al. 1988). In this population, it was proposed that the probability of the acquired toxoplasmosis inducing ocular disease is similar to that observed for congenital toxoplasmosis (Martins et al. 1990). In the present study, it was observed that the presence of retinal cysts occurs in a high percentage of the animals with the acquired form of the disease, that is, $50 \%$ of the pregnant females, $75 \%$ of the non pregnant females and $50 \%$ of the males presented retinal cysts. Thus, C. callosus has demonstrated to be a good experimental model for both acquired and congenital ocular toxoplasmosis.

In contrast, $C$. callosus had showed to be an unsuitable experimental model for induction of autoimmune uveitis. In the present study, after purification of S-antigen, the electrophoretic profile analyzed by SDS-PAGE and stained by silver showed an unique band of approximately $50 \mathrm{kDa}$, as described by Zigler-Jr et al. (1984). It was observed that the $\mathrm{S}$-antigen did not demonstrate to be uveitogenic in none of the experimental groups of animals. There are reports at the literature demonstrating that, from 7 to 21 days after immunization with small doses of S-antigen, it is possible to induce EAU (Wacker et al. 1977, Rao et al. 1979, $\mathrm{Li}$ et al. 1994). Intradermal or subcutaneous routes of purified S-antigen cause an organ-specific uveoretinitis in about 14 days in the majority of the species so far studied and the inflammatory disease is induced in a dose-dependent way (Mahlberg 1989).

In the present study, no success was obtained even when several doses $(6,12,25$ and $50 \mathrm{mg})$ of purified S-antigen + CFA were previously tested in attempt to induce EAU by intradermal route (data not showed). Further, inoculation of purified Santigen $(50 \mathrm{mg}$ ) with or without different adjuvants by intradermal or intramuscular routes were also tested. At 21 days post-immunization, the presence of ocular lesion was not verified by histopathological analysis. Three hypothesis may be raised: (1) S-antigen obtained in the described conditions is not uveitogenically active; (2) the immunization protocol was not appropriate to induce autoimmune uveitis or (3) C. callosus is not a susceptible animal to present uveitis induced by systemic contact with S-antigen.

The antibody titers detected for S-antigen by ELISA showed no correlation with activity of the disease, as already described by Forrester et al. (1989). Antibodies to S-antigen detected later on in animals infected with $T$. gondii demonstrated that the ocular lesions caused by this parasite might induce S-antigen exposition and then stimulate the production of antibodies against this retinal component.

By WB analysis, it was verified that the presence of CFA appears to be necessary for production of antibodies anti-S-antigen and that jacalin may not constitute as a good reinforcement for $\mathrm{S}$ antigen or CFA. Thus, the adjuvants tested together with S-antigen did not demonstrate enough sensitivity to induce autoimmune uveitis in C. callosus. On the other hand, T. gondii can induce autoimmune uveitis in the present experimental model, probably by the exposition of retinal antigens as a result of the inflammatory response to the parasitic antigens.

It can be concluded that $C$. callosus may constitute in a promising model for study both congenital and acquired ocular toxoplasmosis, particularly when it is important to make sure that a non autoimmune process is involved in the genesis of the ocular infection.

\section{ACKNOWLEDGMENTS}

To Dr Ademir Rocha from Department of Pathology of Universidade Federal de Uberlândia for helpful discussion concerning the histopathologic findings. To Dr Neide Maria da Silva for her important help during documentation of this work.

\section{REFERENCES}

Brown CR, Hunter CA, Estes RG, Beckmann E, Forman J, David C 1995. Definitive identification of a gene that confers resistance against Toxoplasma cyst burden and encephalitis. Immunology 85: 419-428. 
Dutton GN 1989. Toxoplasmic retinochoroiditis - A historical review and current concepts. Ann Acad Med 18: 214-221.

Favoreto-Jr S, Ferro EAV, Clemente D, Silva DAO, Mineo JR 1998. Experimental infection of Calomys callosus (Rodentia, Cricetidae) by Toxoplasma gondii. Mem Inst Oswaldo Cruz 93: 103-107.

Forrester JV, Stott DI, Hercus KM 1989. Naturally occurring antibodies to bovine and human retinal Santigen: a comparison between uveitis patients and healthy volunteers. Brit J Ophthal 73: 155-159.

Gazzinelli RT, Brézin A, Li Q, Nussenblatt RB, Chan CC 1994. Toxoplasma gondii: Acquired ocular toxoplasmosis in the murine model, protective role of TNF-a and IFN-g. Exp Parasitol 78: 217-229.

Gonçalves ACP, Yamamoto JH 1997. Toxoplasmose ocular. Aspectos imunológicos. Rev Med São Paulo 76: $130-141$.

Laemmli UK 1970. Cleavage of structural proteins during the assembly of the head of bacteriophage T4. Nature 277: 680-685.

Li Q, Abe T, Kikuchi T, Nussenblatt RB, Shinohara T, Chan CC 1994. Corticosteroids enhance S-antigen expression in nonretinal ocular tissues of rats with experimental autoimmune uveitis. Exp Mol Pathol 60: 27-38.

Lynfield R, Guerina NG 1997. Toxoplasmosis. Ped Rev 18: 75-83.

Mahlberg K 1989. Purification of bovine and human retinal S-antigen using immunoabsorbent polymer particles. Ophthal Res 21: 126-133.

Martins MC, Silveira CM, Jamra LF, Barros PM, BelfortJr R, Rigueiro MP, Neves RA 1990. Isolamento de Toxoplasma gondii de carnes e derivados, provenientes de região endêmica de toxoplasmose ocular- Erechim-R.S. Arq Bras Oftal 53: 60-66.

Mello DA 1981. Studies on reproduction and longevity of Calomys callosus under laboratory conditions (Rodentia, Cricetidae). Rev Bras Biol 41: 841-843.

Mineo JR, Camargo ME, Ferreira AW 1980. Enzymelinked immunosorbent assay for antibodies to Toxoplasma gondii polysaccharides in human toxoplasmosis. Infect Immun 27: 283-287.

Moore KL 1990. Embriologia Clínica, 4a. ed., Editora Guanabara Koogan, Rio de Janeiro, 354 pp.
Newman PE, Ghosheh R, Tabbara KF, O'Connor R, Stern W 1982. The role of hypersensitivity reactions to Toxoplasma antigens in experimental ocular toxoplasmosis in non human primates. Am J Ophthall 94: 159-164.

Nogueira SA, Moreira RB, Pereira NG 1996. Toxoplasmose: diagnóstico e tratamento. J Bras Med 71: 38-44.

Nussenblatt RB, Gery I, Ballintine E 1980. Cellular immune responsiveness of uveitis patients to retinal Santigen. Am J Ophthal 89: 173-179.

O'Connor GR 1983. Factors related to the initiation and recurrence of uveitis XL Edward Jackson Memorial Lecture. Am J Ophthal 96: 577-599.

Rao NA, Wacker WB, Marak GE 1979. Experimental allergic uveitis: clinicopathologic features associated with varying doses of S-antigen. Arch Ophthal 97: 1954-1958.

Roque-Barreira MC, Campos-Neto A 1985. Jacalin: an IgA-binding lectin. J Immunol 134: 1740-1743.

Rothova A, Knapen F van, Baarsma GS, Kruit PJ, Loewer-Sieger DH, Kijlstra A 1986. Serology in ocular toxoplasmosis. B J Ophthal 70: 615-622.

Silveira C, Belfort-Jr R, Burnier M, Nussenblatt RB 1988. Acquired toxoplasmic infection as the cause of toxoplasmic retinochoroiditis in families. Am J Ophtalm 106: 362-364.

Towbin H, Staehelin T, Gordon J 1979. Electrophoretic transfer of proteins from polyacrylamide gels to nitrocellulose sheets: procedure and some applications. Proc Natl Acad Sci USA 76: 4350-4354.

Wacker WB, Donoso LA, Kalsow CM, Yankeelov-Jr JA, Organisclak DT 1977. Experimental allergic uveitis. Isolation, characterization, and localization of a soluble uveitopathogenic antigen from bovine retina. J Immunol 119: 1949-1958.

Wilson MB, Nakane PK 1978. Antibody conjugated to horse-radish peroxidase, p. 215-224. In W Kanpp, $\mathrm{K}$ Holubar, G Wick (eds), Immunofluorescence and Related Staining Technique, Elsevier North Holland Biomedical Press, Amsterdam.

Zigler-Jr JS, Mochizuki M, Kuwabara T, Gery I 1984. Purification of retinal S-antigen to homogeneity by the criterion of gel electrophoresis silver staining. Invest Ophthal Vis Sci 25: 977-980. 